\title{
Vacinação para a gripe sazonal em Internos do Ano Comum
}

ANA SANCHES, NUNO BARBOSA, PATRÍCIA PEDRO, RAQUEL MARTINS, SÉRGIO CASELHOS, TRACY GOUVEIA*

\section{RESUMO}

Objectivos: 0 objectivo global desta investigação é averiguar o grau de adesão à vacinação da gripe sazonal de 2006/2007 e as suas motivações em Internos do Ano Comum (IAC). Constituem objectivos específicos determinar a taxa de vacinados, a taxa dos que pretendem vacinar-se, averiguar a importância que os IAC atribuem à vacinaccão, identificar as razões para a adesão/não adesão e identificar estratégias de incentivo à vacinação.

Tipo de estudo: Estudo descritivo transversal.

Local: 0 inquérito esteve alojado no seguinte site da Internet: http://vacinagripe.no-ip.org

População: Internos do Ano Comum a exercerem em Portugal no ano de 2006.

Métodos: Obteve-se uma amostra de conveniência constituida por 136 IAC. Foram considerados como critérios de inclusão o ser Licenciado em Medicina a frequentar o Ano Comum em Portugal, e de exclusão o não responder ao questionário e/ou questionários incorrectamente preenchidos. Estudaram-se as seguintes variáveis: sócio-demográficas (sexo e local de trabalho), caracterização da adesão à vacinação da gripe sazonal, motivaç̃oes para a adesão e não adesão à vacinação, o grau de importância atribuído à vacinação na classe médica, caracterização de estratégias de incentivo à vacinação da gripe sazonal e o conhecimento/desconhecimento da classe médica pertencer a um grupo de risco. Os dados foram tratados no Epi Info ${ }^{T M}$ Versão 3.3.2.

Resultados: A percentagem de IAC vacinados foi de 33,1\% ( $n=45)$. As principais motivações apontadas para a vacinaç̃o foram "proteger-me da doença», "proteger os doentes" $e$ "tenho fácil acesso à vacina da gripe», e para a não vacinação "desinteresse", "não tive tempo» $e$ "considero a vacina para a gripe pouco eficaz".

Conclusão: A importância atribuida pelos IAC à vacinação, o facto de se considerarem um grupo de risco, a existência de uma taxa considerável dos que pretendem vacinar-se, bem como as motivações encontradas, poderão constituir um bom ponto de partida para futuras campanhas.

Palavras-chave: Vacina; Gripe; Internos do Ano Comum.
*Alunos do $6^{\circ}$ Ano da Faculdade de Ciências Médicas da Universidade Nova de Lisboa. Departamento de Saúde Pública.

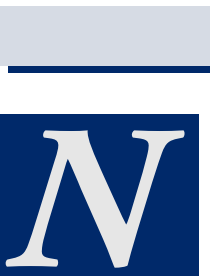

\section{INTRODUCÃ̃O} tram as atenções numa hipotética pandemia de gripe aviária, é necessário não esquecer que epidemias de gripe surgem quase todos os anos, em vários pontos do globo, ${ }^{1}$ afectando comunidades extensas, com custos sociais e des- pesas de saúde extremamente elevados. ${ }^{2}$ Segundo a Organização Mundial de Saúde (OMS), durante estas epidemias anuais, a taxa de ataque global é de 5 a 10\% na população adulta e de 20 a $30 \%$ nas crianças. ${ }^{3}$

A gripe é uma doença respiratória aguda que afecta as vias respiratórias superiores e inferiores. É caracterizada por um início abrupto de sintomas sistémicos, como cefaleias, febre, mialgias e calafrios, acompanhados de sinais respiratórios, nomeadamente tosse e odinofagia. O quadro clínico é, contudo, muito variável.

As complicações da gripe ocorrem, mais frequentemente, em doentes com idade superior a 64 anos e em pessoas com doenças crónicas, incluindo patologia cardíaca, pulmonar, renal, diabetes mellitus, hemoglobinopatias, ou imunossupressão. Existe, também, uma maior predisposição para complicações em grávidas a partir do segundo trimestre.

A complicação mais importante (pela sua frequência e gravidade) é a pneumonia, por vezes associada a sobre-infecção bacteriana. As outras complicações pulmonares associadas à gripe incluem: agravamento da doença pulmonar obstrutiva crónica, exacerbação de bronquite crónica ou de asma e crupe (em crianças). A gripe associa-se também a sinusite e otite média. As complicações extra-pulmonares incluem: sindrome de Reye, miosite, rabdomiólise ou mioglobinúria. As doenças do sis- 
tema nervoso central, como encefalite, mielite transversa e síndrome Guillain-Barré (SGB), têm sido descritas durante a infecção gripal. Esta doença pode causar um agravamento progressivo de patologias cardiovasculares, pulmonares e renais pré-existentes, alterações que são por vezes irreversiveis e que levam à morte.

A gripe é causada por um vírus RNA, pertencente à família dos Orthomyxoviridae e ao género Influenza. Existem três serotipos deste vírus, designados de $\mathrm{A}$, $\mathrm{B}$ ou $\mathrm{C}$, de acordo com as características antigénicas das nucleoproteínas e da matriz. O serotipo A possui vários subtipos, consoante as glicoproteínas de superficie (hemaglutinina e neuraminidase) que apresenta. A hemaglutinina $(\mathrm{H})$ é responsável pela adesão do vírus às células do aparelho respiratório e a neuraminidase $(\mathrm{N})$ pela libertação dos viriões, a partir da célula hospedeira. Estas glicoproteínas são capazes de desencadear uma resposta imunitária no organismo hospedeiro, sendo a $\mathrm{H}$ a mais imunogénica. Conhecem-se hoje, para o vírus Influenza A, $16 \mathrm{H}$ e $9 \mathrm{~N}$ distintas, estando somente os subtipos $\mathrm{H}_{1}$, $\mathrm{H}_{2}, \mathrm{H}_{3}, \mathrm{~N}_{1}$ e $\mathrm{N}_{2}$ associados a surtos extensos de doença em humanos. Os vírus de Influenza B e C não são classificados por subtipos, visto as variações intratípicas serem menos frequentes do que no virus A. Os vírus Influenza A e $B$ são os patogénios principais da gripe em humanos.

Os virus da gripe possuem uma capacidade única de sofrer alterações ou variações genéticas, que se traduzem em variações antigénicas. Estas variações classificam-se em dois tipos: antigenic shift e antigenic drift. $\mathrm{O}$ antigenic shift consiste numa variação antigénica major em que ocorre recombinação de segmentos genómicos de diferentes subtipos do virus A. Os subtipos do vírus A têm, como reservatório natural, as aves aquáticas selvagens. Raramente, esta variação antigénica resulta em novas estirpes pandémicas por recombinação entre subtipos humanos e animais. Quando subtipos animais conseguem, sem recombinação com vírus humanos, causar directamente doença humana, a letalidade pode ser elevada. Um exemplo disto, foram os casos de $\mathrm{H}_{5} \mathrm{~N}_{1}$ em 1997, em Hong Kong, de origem aviária, onde se confirmaram 18 casos de infecção humana, seis dos quais mortais. Outra variação antigénica é o antigenic drift, em que as variações são menores e resultam de alterações na sequência de bases codificadoras dos aminoácidos das glicoproteínas de superficie, nomeadamente da H. A variante daí resultante possui a capacidade de resistir à imunidade adquirida por uma infecção prévia ou pela vacinação. Estas variações são características da evolução dos vírus Influenza A e B e são responsáveis pelos surtos comuns e epidemias de gripe.

Devido a esta grande variabilidade antigénica do virus da gripe, a OMS gere um sistema de vigilância global, que integra informação genética e antigénica actualizada dos vírus em circulação, sendo esta informação fundamental para a recomendação anual sobre a composição apropriada da vacina a ser comercializada em cada época da gripe. Em Portugal, esta vigilância epidemiológica está a cargo do Instituto Nacional de Saúde Dr. Ricardo Jorge e do Observatório Nacional de Saúde, em colaboração com a Rede de Médicos Sentinela, que assegura a caracterização clínica, epidemiológica e laboratorial da doença. ${ }^{4}$

A transmissão do vírus é feita, sobretudo, através da inalação de micro-gotículas de secreções respiratórias de pessoas infectadas. O período de incubação varia de um a cinco dias. O período de transmissão decorre do primeiro ao segundo dia antes do aparecimento dos sintomas até ao sétimo dia após o aparecimento destes. Em bebés e crianças jovens pode durar até duas 
semanas.

Um determinante major na extensão e severidade dum surto de gripe é o grau de imunidade da população em risco. São, sobretudo, os anticorpos circulantes que conferem protecção contra as formas clínicas da doença, enquanto que as IgA, elaboradas ao nivel das mucosas, conferem resistência contra a infecção. O efeito dos anticorpos, induzidos por uma determinada estirpe, pode diminuir ou desaparecer no seguimento dum antigenic drift. ${ }^{3}$

Os anticorpos antigripais podem persistir no sangue durante meses ou anos. ${ }^{3}$ No entanto, a protecção conferida pela vacina tem alguma variação inter-individual e temporal. Após a vacinação, o nivel de anticorpos que confere protecção é, geralmente, atingido ao fim de duas semanas. Este periodo pode ser mais prolongado nas crianças vacinadas pela primeira vez. A protecção persiste por um período inferior a um ano. Nos idosos, os níveis de anticorpos podem descer abaixo dos níveis de protecção em quatro meses. ${ }^{4}$

Assim, a vacinação anual contra a gripe sazonal é considerada, hoje, a melhor forma de prevenir a doença e de reduzir o impacto das epidemias. O principal objectivo desta vacinação é evitar as formas graves e complicações da doença, conduzindo a uma redução da incidência da doença grave e da mortalidade prematura. ${ }^{4}$

A OMS recomenda que, para a época de 2006-2007 no Hemisfério Norte, as vacinas trivalentes contra a gripe contenham estirpes virais idênticas a: A/New Caledonia/20/99(H1N1); A/ /Wisconsin/67/2005(H3N2) 1; B/Malaysia/2506/20042. Estas estirpes são usadas por se prever serem representativas dos virus Influenza que irão circular durante a época da gripe no hemisfério Norte, de Novembro de 2006 a Abril de $2007 .^{5}$

As vacinas antigripais podem ser inactivadas ou vivas atenuadas. Em
Portugal, as vacinas disponiveis são inactivadas. ${ }^{4}$ Nestas, os virus são tornados não-infecciosos. ${ }^{6}$ Podem ser constituídas por virus inteiros, vírus fragmentados ou subunidades (HA e NA purificados). Como o vírus é feito crescer, inicialmente, em ovos embrionados, as vacinas podem conter quantidades residuais de proteínas do ovo. ${ }^{6}$

As vacinas devem ser administradas por via intramuscular ou subcutânea profunda. Como o pico da actividade gripal tem ocorrido entre Novembro e Fevereiro, deve ser administrada a partir de Outubro, principalmente nos idosos e imunodeprimidos. Pode, porém, ser administrada durante toda a época gripal. ${ }^{4,6}$

São contra-indicações da vacina da gripe: antecedentes de uma reacção grave a uma dose anterior da vacina ou de reacção anafiláctica a qualquer dos componentes da vacina (excipientes ou proteínas do ovo). ${ }^{3}$

As vacinas trivalentes inactivadas (VTI) são, geralmente, muito seguras. Com as vacinas de vírus inteiros, 15$-20 \%$ dos vacinados (sobretudo crianças) têm reacções locais durante um a dois dias e, numa minoria de vacinados, ocorrem reacções generalizadas, passageiras, como febre, mau estado geral e mialgias, nas seis a doze horas que se seguem à vacinação. As restantes vacinas inactivadas têm, geralmente, uma reactividade menor. ${ }^{3}$ Nalgumas estações gripais, as VTI foram associadas a um ligeiro aumento do risco de SGB em adultos. No entanto, não foi possivel confirmar uma relação causal entre a gripe e este sindrome, por insuficiência de dados. ${ }^{4}$

A efectividade da vacina é variável de ano para ano, pois depende do grau de concordância antigénica entre as estirpes contidas na vacina e as estirpes em circulação, da idade e do grau de imunocompetência do vacinado. Depende, também, dos objectivos considerados (culturas séricas positivas para o vírus, 
seroconversão, etc.) e exactidão do diagnóstico. Se houver concordância antigénica, a vacina pode prevenir 70 a $90 \%$ dos casos de doença laboratorialmente confirmada. ${ }^{3,4}$ A vacinação da população idosa não institucionalizada pode reduzir o número de internamentos em 25 a 39\% e a mortalidade global em 39 a 75\%, durante a época gripal. ${ }^{3,4}$ Nos idosos institucionalizados a vacina contra a gripe pode reduzir os internamentos (por todas as causas) em 50\%, o risco de pneumonia em 60\% e o risco de morte (por todas as causas) em 68\%.3,4

A quota de vacinas contra a gripe sazonal atribuída a cada país é limitada pelo que, segundo a Direcção-Geral da Saúde (DGS), ${ }^{4}$ a prescrição da vacina em Portugal deve seguir um conjunto de orientações por ela definido, de modo a não comprometer a disponibilidade de vacinas para os grupos populacionais que mais dela beneficiam. Deste modo, recomenda a vacinação dos indivíduos (com mais de seis meses de idade), incluídos nos seguintes grupos populacionais:

- Pessoas com alto risco de desenvolver complicações pós infecção gripal, ou seja:

- Indivíduos com idade igual ou superior a 65 anos, particularmente os residentes em lares ou outras instituições;

- Doentes crónicos que apresentem doenças crónicas pulmonares ou cardíacas, doenças crónicas que necessitem de seguimento médico regular (renais, hepáticas, hematológicas, metabólicas ou neuromusculares, que comprometam a função respiratória, a eliminação de secreções ou com risco aumentado de aspiração de secreções) ou imunodepressão;

- Indivíduos residentes ou internados por períodos prolongados em instituições prestadoras de cuidados de saúde;

- Crianças e adolescentes (até aos
18 anos) em tratamento prolongado com salicilatos, pelo risco de desenvolver sindroma de Reye após uma infecção gripal;

- Grávidas que, em Outubro, estejam no segundo ou terceiro trimestre da gravidez.

- Pessoas com probabilidade acrescida de transmitir o vírus aos grupos anteriores:

- Pessoal dos serviços de saúde e de outros serviços prestadores de cuidados, com contacto directo com as pessoas acima referidas, mesmo que vacinadas.

- Coabitantes de crianças, com menos de seis meses de idade e com risco elevado de desenvolver complicações.

- Profissionais envolvidos em operações de abate sanitário de aves potencialmente infectadas com vírus da gripe.

Em 2003, a Assembleia Mundial da Saúde pediu aos Estados Membros, dotados duma política de vacinação antigripal, para aumentarem a cobertura vacinal de todos os grupos de alto risco e de fixarem o objectivo de uma cobertura vacinal superior a $50 \%$ nas pessoas idosas em 2006 e de 75\% em 2010. ${ }^{3}$ Este objectivo, adoptado pela DGS, é considerado uma das prioridades para 2006-2007. ${ }^{4}$ As estimativas revelam que, em Portugal, para a população em geral, nas épocas de 2004/2005 e de $2005 / 2006$, as percentagens de pessoas vacinadas foram, respectivamente, de $15,4 \%$ e $19,1 \%$, e nos indivíduos com 65 e mais anos de 39,0\% e 41,6\%.

A DGS tem, ainda, como objectivo principal em 2006/2007, aumentar a cobertura vacinal em profissionais de saúde (PS). ${ }^{4}$ De facto, existem beneficios da vacinação destes profissionais, tanto no prognóstico dos doentes, como na redução do absentismo ou na diminuição da infecção entre o pessoal de saúde. ${ }^{7-11}$

Um estudo revela que $23 \%$ dos PS, 
não imunizados, adquiriram serologia positiva para o vírus Influenza, durante uma estação gripal de intensidade ligeira. Destes, 59\% não se recordam de ter tido gripe e $28 \%$ não se lembram de ter contraído qualquer infecção respiratória, o que aponta para uma elevada proporção de casos assintomáticos. ${ }^{11}$ Os indivíduos infectados, sintomáticos ou assintomáticos, podem transmitir o virus a pessoas que tenham um elevado risco de desenvolver complicações da gripe. Foi demonstrado que niveis elevados de vacinação entre os PS estão associados a uma menor incidência de casos de infecção nosocomial por Influenza, entre os doentes hospitalizados. ${ }^{8-10}$ Um estudo demonstrou uma redução de $40 \%$ da mortalidade total, durante o Inverno, em idosos internados, aquando da vacinação de 50\% do pessoal de saúde. ${ }^{9,10}$

Noutro estudo, a vacinação dos PS levou a uma redução da infecção entre estes trabalhadores, de $88 \% .{ }^{11}$ Alguns estudos sugerem uma redução do absentismo destes profissionais com um aumento da taxa de vacinação. ${ }^{11,12}$ No entanto, esta não é estatisticamente significativa, limitação atribuivel ao facto de alguns continuarem a trabalhar apesar da doença. ${ }^{11,13}$

Apesar dos beneficios acima referidos, a cobertura vacinal dos PS nos EUA mantém-se baixa (menor que $50 \%)^{6}$ e, em Portugal, não existem dados publicados sobre esta matéria.

Um estudo de revisão, ${ }^{14}$ que abrange trabalhos realizados em vários países do mundo (Canada, Estados Unidos da América, Itália, Inglaterra, Israel...), entre 1985 e 2002, revelou uma taxa de vacinação que varia de $2,1 \%$ a $82 \%$. Este estudo identifica, como factores para esta variabilidade, as características das campanhas e os factores politicos ou culturais. As taxas reduzidas de vacinação associam-se a dois principais obstáculos: a) ideias erradas sobre a gripe e os seus riscos, sobre o pa- pel dos PS na sua transmissão e sobre a importância da vacinação anual e b) percepção de difícil acesso à vacina. Os estudos com melhores taxas de vacinação apresentam as seguintes características: notificação dos PS (através da comunicação social, de convites individuais, de cartazes ou de panfletos), educação (através de sessões no serviço, conferências ou filmes educacionais) e vacinação (gratuita e de fácil acesso, através de carros móveis ou em locais próprios para vacinação). Os motivos para a vacinação incluem: protecção do próprio, protecção dos doentes, gratuitidade da vacina/fácil acesso e protecção da saúde de familiares. Para a não vacinação, os motivos são variados: medo dos efeitos adversos, mito da vacina causar gripe, considerar não correr risco de infecção, inconveniência das horas/locais para vacinação, dúvidas quanto à gravidade da doença, ineficácia da vacina e medo de injecções.

Apesar da grande variedade de estudos sobre a vacinação em PS, aqueles que têm por objecto de estudo médicos ainda em formação são muito escassos, não nos permitindo tirar conclusões definitivas sobre a adesão à vacinação destes profissionais. Estes estudos apresentam taxas de vacinação que variam de 38,3\% a 97\%. ${ }^{15-17}$

Em Portugal, o Ano Comum corresponde ao processo de formação inicial do internato médico. Tem a duração de 12 meses e engloba os seguintes estágios: Medicina Interna (quatro meses), Pediatria Geral (dois meses), Obstetrícia (um mês), Cirurgia Geral (dois meses), Cuidados de Saúde Primários (três meses), ${ }^{18}$ proporcionando a estes médicos um contacto próximo com os doentes. Tendo em conta as recomendações da DGS para este ano e a ausência de estudos nesta área, torna-se fundamental conhecer a adesão destes profissionais à vacina antigripal, assim como as suas motivações. 


\section{OBJECTIVOS}

\section{Objectivo global}

Com este trabalho propõe-se averiguar o grau de adesão à vacinação da gripe sazonal de 2006/2007 e as suas motivações, de entre a população de Internos do Ano Comum, com o intuito de fazer um retrato desta situação no actual panorama português.

\section{Objectivos específicos}

1. Determinar numa amostra de médicos Internos do Ano Comum em 2006:

- a taxa de vacinados para a gripe sazonal;

- a taxa dos que pretendem fazê-lo.

2. Averiguar a importância que os Internos do Ano Comum atribuem à vacinação para a gripe sazonal.

3. Identificar as razões para a adesão/ /não adesão à vacinação.

4. Identificar estratégias de incentivo à vacinação da gripe sazonal nos Internos do Ano Comum em 2006.

\section{Metodologia}

\section{Tipo de estudo}

Estudo descritivo transversal.

O estudo foi aprovado pelo Departamento de Saúde Pública da Faculdade de Ciências Médicas da Universidade Nova de Lisboa.

\section{População Alvo}

A população escolhida foi a de Internos do Ano Comum a exercer em Portugal no ano de 2006.

\section{Técnica de amostragem}

Amostra de conveniência.

\section{Critérios de selecção da amostra Critérios de INCLUSÃo}

- Licenciados em Medicina a frequentarem o Ano Comum em Portugal.

\section{Critérios de Exclusão}

- Não responder ao questionário;

- Questionários incorrectamente preenchidos.

A amostra foi constituída por individuos de ambos os sexos, licenciados em Medicina, e a frequentar o Ano Comum.

\section{Amostra}

Responderam ao questionário 144 indivíduos, dos quais oito eram não Internos. Assim, obteve-se uma amostra de 136 Internos do Ano Comum de entre uma população de $823 .{ }^{19}$

\section{Escolha do local}

O inquérito esteve alojado no seguinte site da Internet: http://vacinagripe.noip.org durante 8 dias, onde foi possivel aos Internos votarem electronicamente.

O questionário foi também impresso em papel e entregue em mão a um grupo de Internos (15), a trabalhar em diferentes hospitais da Região Norte (Porto). Nenhum Interno pôde votar mais do que uma vez.

\section{Processo de colheita de dados}

A colheita de dados realizou-se entre os dias 20 e 27 de Outubro.

Durante as fases de preparação e colheita de dados foram considerados os seguintes aspectos:

Obteve-se uma lista de 140 contactos de $e$-mail de alguns Internos do Ano Comum.

A cada contacto desta lista foi enviado um e-mail com o link do site do questionário, solicitando que respondessem ao inquérito e pedindo que reencaminhassem.

As respostas ao inquérito via $w e b$ foram anónimas, não tendo sido solicitada qualquer identificação pessoal. No entanto, foi associado a cada questionário a data e hora em que foi submetido e o IP ("Internet Protocol») do computador. Estas duas informações permitiram eliminar respostas consecutivas, num espaço temporal muito curto, 
no mesmo computador.

Os questionários entregues em mão, em suporte de papel, foram preenchidos na presença de um dos investigadores, que teve o cuidado de informar o Interno de que, caso tivesse conhecimento do formato electrónico, não voltasse a preencher o questionário.

As respostas dadas em papel foram posteriormente inseridas por um dos investigadores no questionário electrónico.

O questionário era voluntário, anónimo e confidencial, preenchido pelo próprio, via Internet ou em formato de papel.

\section{Pré-teste}

O pré-teste foi aplicado entre os dias 16 e 17 de Outubro. Responderam os próprios investigadores, alguns colegas do curso de Medicina e médicos, totalizando 25 pré-testes. O preenchimento não suscitou dúvidas relevantes, pelo que se manteve a sua estrutura para aplicação futura no estudo.

\section{Variáveis em estudo}

Este estudo pretendia avaliar as seguintes variáveis:

- Sócio-demográficas (sexo e local de trabalho);

- Caracterização da adesão à vacinação da gripe sazonal;

- Motivações para a adesão e não adesão à vacinação da gripe sazonal;

- O grau de importância atribuído à vacinação na classe médica;

- Caracterização de estratégias de incentivo à vacinação da gripe sazonal;

- Conhecimento/desconhecimento da classe médica pertencer a um grupo de risco.

\section{Material utilizado}

- Servidor (computador) com acesso ADSL à Internet em ambiente Windows.

- DNS service provider.

- Base de dados SQL Server 2000.

- Site desenvolvido em ASP.NET com
framework.NET 1.1, e usando o portal DotNetNuke v3.1.

- Microsoft Access ${ }^{\circledR}$.

- Microsoft Word ${ }^{\circledR}$.

- Epi Info ${ }^{\mathrm{TM}}$ Versão 3.3.2.

- Canetas, papel, suporte rígido para escrever.

- Telefones e/ou telemóveis e computadores.

\section{Orçamento}

Participaram neste trabalho seis investigadores e um consultor informático externo, durante seis semanas. Foram efectuados gastos logísticos, num total de 1.020 Euros, descriminados a seguir:

\begin{tabular}{|c|c|}
\hline ITENS & CUSTOS \\
\hline $\begin{array}{l}\text { Desenvolvimento do site } \\
\text { (com levantamento de requisitos, } \\
\text { construção da base de dados, layout } \\
\text { web do questionário, alojamento } \\
\text { e colocação online do site) }\end{array}$ & 800 \\
\hline Telecomunicações & 100 \\
\hline $\begin{array}{l}\text { Deslocações: combustível e } \\
\text { bilhetes de transporte }\end{array}$ & 70 \\
\hline $\begin{array}{l}\text { Monografia e Protocolo } \\
\text { (impressões, fotocópias...) }\end{array}$ & 50 \\
\hline Total & 1.020 \\
\hline
\end{tabular}

\section{Tratamento dos dados}

Foi criada uma base de dados no Microsoft Access ${ }^{\circledR} X P$, posteriormente importada para o Epi Info ${ }^{\mathrm{TM}}$ Versão 3.3.2, para tratamento estatístico dos dados e elaboração de gráficos e/ou tabelas. Para a redacção da monografia utilizou-se o Microsoft Word $^{\circledR}$. Foram também utilizados o Microsoft Excel ${ }^{\circledR}$ e o PowerPoint ${ }^{\circledR}$.

\section{Resultados}

\section{Descrição da Amostra}

A amostra de conveniência é constituída por 136 individuos de ambos os sexos, Internos do Ano Comum, vacina- 
dos ou não para a gripe sazonal. Verifica-se uma predominância do sexo feminino, com 60,3\% (n=82). Os homens que responderam a este inquérito correspondem a 39,7\% (n=54). A distribuição de Internos por local de trabalho está representada na Figura 1.

\section{Adesão à vacinação e}

caracterização dos Internos

Vacinados/Não Vacinados

Como está representado na Figura 2, $66,9 \%$ dos Internos não aderiram à vacinação.

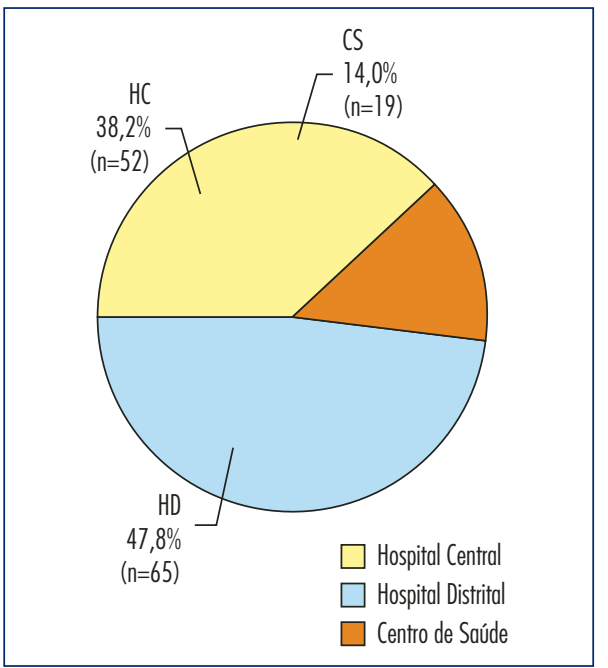

Figura 1. Distribuição de Internos por local de trabalho.

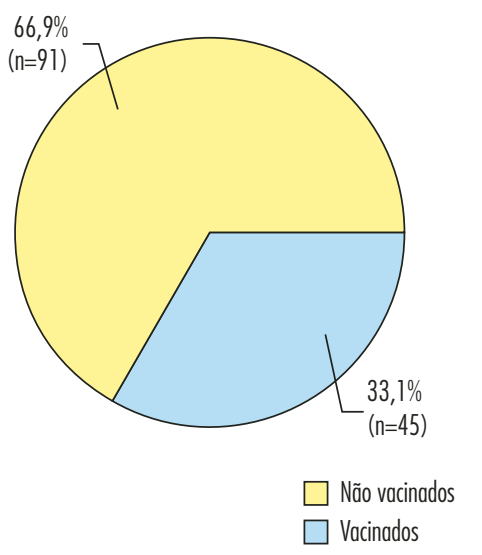

Figura 2. Distribuicão da amostra por vacinados/ /não vacinados

\begin{tabular}{|lccc|}
\hline \multicolumn{4}{|c|}{ QUADRO I } \\
\hline \multicolumn{3}{|c|}{$\begin{array}{c}\text { DISTRIBUIÇ̃̃O DE VACINADOS/NÃO VACINADOS } \\
\text { NA AMOSTRA ESTRATIFICADA PARA O SEXO }\end{array}$} \\
\hline \multicolumn{4}{|c|}{ Sexo } \\
\hline Vacinado/ & \multicolumn{3}{c}{} \\
/ Não Vacinado & Feminino & Masculino & Total \\
\hline não vacinado & 51 & 40 & 91 \\
Row \% & 56,0 & 44,0 & 100,0 \\
Col \% & 62,2 & 74,1 & 66,9 \\
\hline vacinado & 31 & 14 & 45 \\
Row \% & 68,9 & 31,1 & 100,0 \\
Col \% & 37,8 & 25,9 & 33,1 \\
\hline TOTAL & 82 & 54 & 136 \\
Row \% & 60,3 & 39,7 & 100,0 \\
Col \% & 100,0 & 100,0 & 100,0 \\
\hline
\end{tabular}

No Quadro I é apresentada a distribuição de vacinados/não vacinados na amostra estratificada para o sexo.

\section{Razões para a vacinação}

Como demonstrado na Figura 3, as três principais razões apontadas pelos Internos para se vacinarem foram:

- Proteger-me da doença;

- Proteger os doentes;

- Ter fácil acesso à vacina. Dos que responderam "Outro":

- Três Internos (25\%) consideraram ser importante a vacinação para a

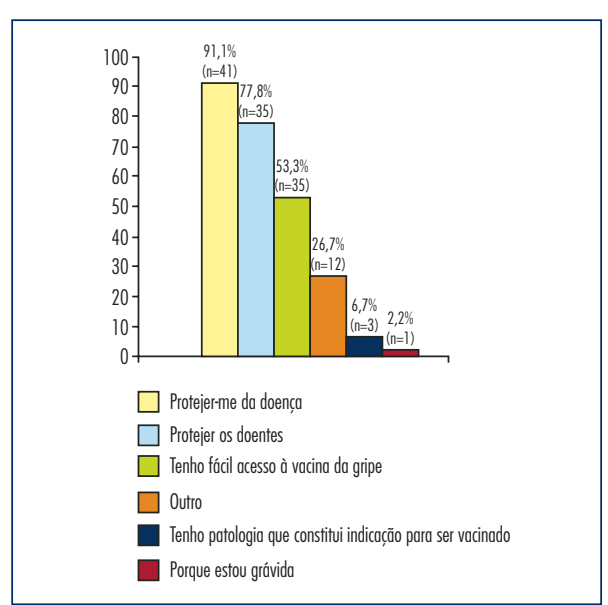

Figura 3. Razões para a vacinação. 


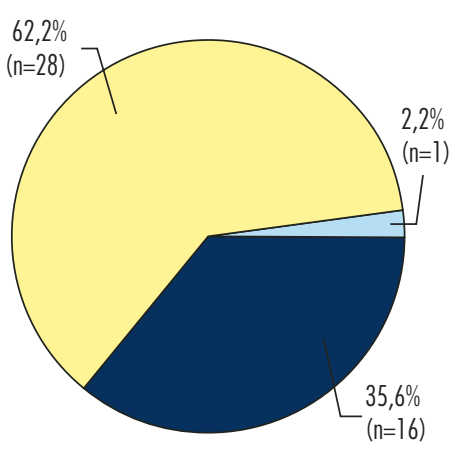

Adquiri gratuitamente no local onde trabalho - Hospital

Adquiri gratuitamente no local onde trabalho - Centro de Saúde Comprei

Figura 4. Meio de Obtenção da vacina.

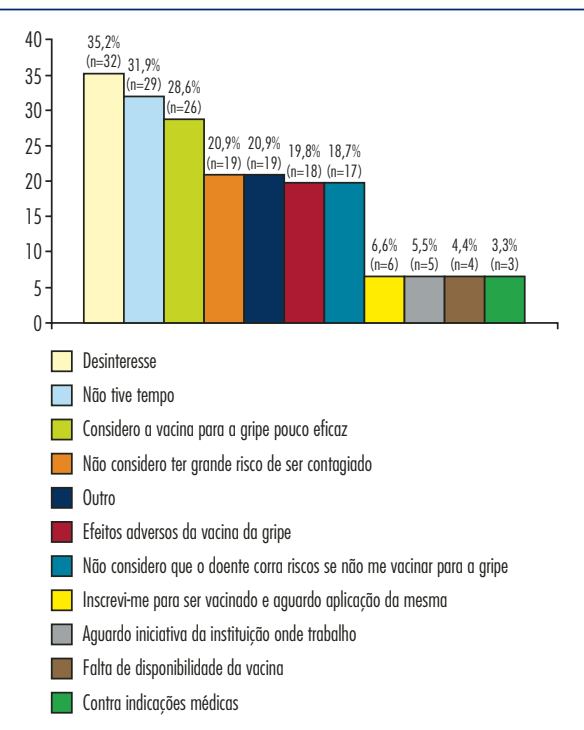

Figura 5. Razões para a não vacinação.

gripe sazonal, por permitir a diminuição do risco de infecção para a gripe das aves;

- Seis (50\%) consideraram ser importante a vacinação pelo facto de pertencerem a um grupo de risco;

- Três (25\%) consideraram a protecção da sua família.

Na Figura 4 estão representados os meios de obtenção da vacina utilizados pelos Internos.

\section{Razões para a não vacinação}

Como se verifica pela análise da Figura 5, as três principais razões apontadas pelos Internos para não se terem vacinado foram:

- Desinteresse;

- Não tive tempo;

- Considero a vacina para a gripe pouco eficaz.

Se NÃo se vacinou, PRETENDE FaZê-LO? Dos não vacinados ( $n=91), 33 \%(n=30)$ pretendiam ainda fazê-lo. Ou seja, 67\% ( $n=61)$ não se vacinaram nem pretendiam fazê-lo.

\section{Campanhas de vacinação}

Noventa e quatro Internos $(69,1 \%)$ tiveram conhecimento da campanha de incentivo à vacinação, enquanto que 42 desconheciam-na (30,9\%). A Figura 6 mostra a distribuição das formas de conhecimento dessas campanhas e o Quadro II o local de trabalho onde obtiveram a informação.

Dos Internos do Ano Comum que referiram ter conhecimento de alguma campanha para a vacinação no local de trabalho $(n=74), 68,9 \%(n=51)$ foi no Hospital e 31,1\% (n=23) no Centro de Saúde.

\section{Importância da vacinação}

Cento e onze internos $(81,6 \%)$ consideram a vacinação da classe médica importante ou muito importante (Figura 7) e a grande maioria $(88,2 \%)$ que os médicos constituem um grupo de risco para a gripe sazonal (Figura 8).

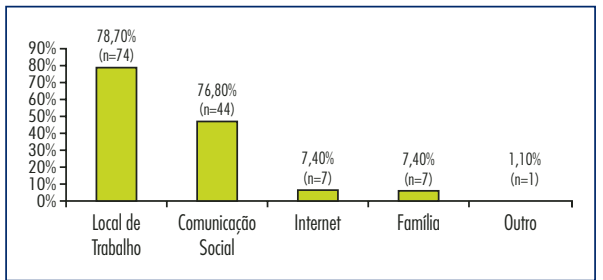

Figura 6. Formas de conhecimento das campanhas para a vacinacão. 


\section{QUADRO |I}

\begin{tabular}{|l}
\hline QUADRO II \\
\hline \multicolumn{4}{|c|}{ DISTRIBUIĈ̣̃O DE CAMPANHAS POR LOCAL DE TRABALHO } \\
\hline \begin{tabular}{lccc|}
\hline Local de trabalho & Frequência & Percentagem & $\begin{array}{c}\text { Percentagem } \\
\text { Cumulativa }\end{array}$ \\
\hline Centro de Saúde & 23 & $31,1 \%$ & $31,1 \%$ \\
\hline Hospital & 51 & $68,9 \%$ & $100,0 \%$ \\
\hline Total & 74 & $100,0 \%$ & $100,0 \%$ \\
\hline
\end{tabular}
\end{tabular}

nados com o conhecimento de uma determinada campanha;

A proporção de vacinados/não vacinados não é significativamente diferente consoante a campanha.

O teste de $\chi^{2}$ com correcção para a continuidade tem um valor de pro-

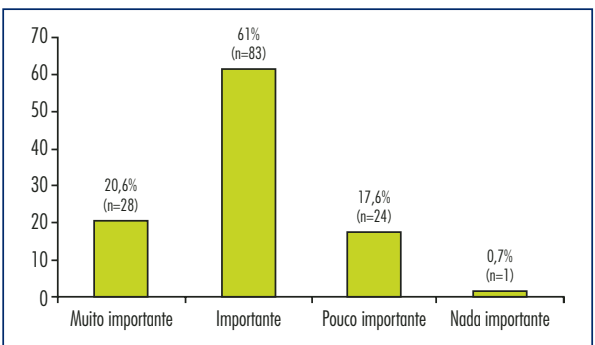

Figura 7. Importância atribuída à vacinação na classe médica.

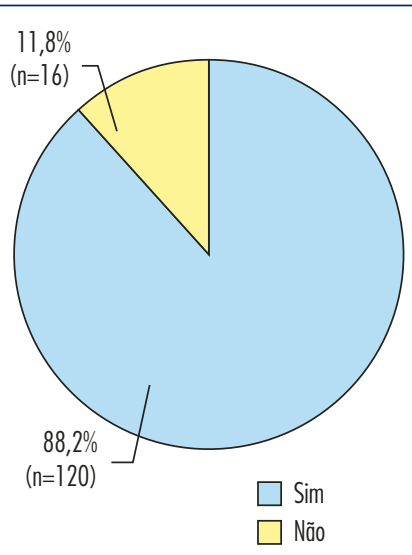

Figura 8. Acha que os médicos constituem um grupo de risco para a gripe sazonal?

\section{Testes estatísticos}

\section{A VARIAÇÃo DA PROPORÇÃo DE} VACINADOS/NÃO VACINADOS VARIA COM $O$ CONHECIMENTO DA CAMPANHA EFECTUADA

$\mathrm{H}_{0}$ : Não há diferenças significativas na proporção de vacinados/não vacinados com o conhecimento de uma determinada campanha;

$\mathrm{H}_{1}$ : Existem diferenças significativas na proporção de vacinados/não vaci- va $(p=0,52)$ superior a $\alpha=0,05$, logo, aceita-se a hipótese nula, pelo que não há diferenças estatisticamente significativas quanto à proporção de vacinados/não vacinados com o conhecimento da campanha efectuada.

\section{A VARIAÇÃo da PROPORÇão dE VACINAdos/} /NÃO VAcINADOS VARIA COM O SEXO

$\mathrm{H}_{0}$ : Não há diferenças significativas na proporção de vacinados/não vacinados relativamente ao sexo;

$\mathrm{H}_{1}$ : Existem diferenças significativas na proporção de vacinados/não vacinados relativamente ao sexo;

A proporção de vacinados/não vacinados não é significativamente diferente consoante o sexo. O teste de $\chi^{2}$ com correcção para a continuidade tem um valor de prova $(p=0,209)$ superior a $\alpha=0,05$, logo, aceita-se a hipótese nula, pelo que não há diferenças estatisticamente significativas quanto à proporção de vacinados/não vacinados entre homens $\mathrm{e}$ mulheres.

\section{DIscussão}

\section{Discussão metodológica}

Tendo como objectivo global avaliar o grau de adesão à vacinação para a gripe sazonal de 2006/2007 e as suas motivações, de entre a população de Internos do Ano Comum, tentou-se idealizar o modo mais simples de aceder à população pretendida. Foi consensual que a melhor forma de abordar o grupo em questão seria através de questionários 
auto-preenchidos, uma vez que se trata de uma população com um grau de escolaridade elevado (ensino superior), pelo que estariam aptos a preenchê-lo correctamente.

Por questões de acessibilidade e recursos, dado que os Internos se encontram distribuídos por todo o país, a maioria deles foi inquirida via Internet, embora tenham sido distribuídos alguns questionários para preenchimento em suporte de papel. Por questões logísticas, o questionário esteve alojado num site que se manteve activo entre os dias 20 e 27 de Outubro. O link de acesso ao site foi divulgado junto de Internos do Ano Comum, a partir de uma lista de contactos de $e$-mail, solicitando o reencaminhamento do mesmo, pelo que se trata de uma amostra de conveniência. A participação foi voluntária e dependente da motivação de cada um, podendo deste modo, constituir um viés. Possivelmente, os indivíduos vacinados estariam mais motivados a responder a um questionário sobre esta temática. A amostra é constituída por um total de 136 indivíduos de uma população de 823.

Pelas razões atrás referidas, a amostra em estudo não pode ser considerada aleatória e representativa da população de Internos do Ano Comum. Por outro lado, como se desconhecem os aspectos demográficos da população de Internos do Ano Comum, as variáveis de caracterização demográfica da amostra, como sexo e local de trabalho, à data do inquérito, não puderam ser comparadas com as da população de Internos, pelo que as observações verificadas neste estudo não poderão ser inferidas para a população em estudo.

A exiguidade de tempo e de recursos obrigaram a que a recolha da informação fosse efectuada num curto espaço de tempo, tratando-se de um estudo descritivo transversal.

Razões logisticas, escassez de tempo, necessidade de evitar respostas contra- ditórias acerca da mesma variável e a necessidade de evitar um questionário demasiado extenso, fizeram com que cada uma das variáveis em estudo fosse geralmente medida apenas por uma questão. No entanto, variáveis como as estratégias de incentivo à vacinação, o conhecimento dos Internos sobre o facto de pertencerem ou não a um grupo de risco, o grau de importância que atribuem à vacinação, são extremamente dificeis de avaliar num só tipo de abordagem. Assim, relativamente aos médicos constituírem um grupo de risco para a gripe sazonal, não fica esclarecido se a escolha efectuada diz respeito ao perigo do médico ser contagiado, ao facto de ser o agente contagioso ou ambas. No que respeita à importância que atribuem à vacina na classe médica, não há a percepção de como essa escolha foi feita ou em que critérios se basearam. A avaliação destas variáveis exigiria uma análise mais exaustiva (mais perguntas por variável e mais específicas, por exemplo) com todas as desvantagens a que se iria associar. Assim, a validade de alguns dos resultados obtidos relativamente à medição real das variáveis referidas não estará totalmente garantida.

Algumas limitações do estudo prendem-se com o próprio questionário enquanto instrumento de medição. Na análise da taxa de vacinação, assim como no estudo de campanhas no local de trabalho, dados observacionais seriam úteis, em complemento do inquérito. No entanto, em Portugal, esta informação não se encontra publicada, nem centralizada, o que torna estes dados de muito dificil acesso.

Para estudar as causas de vacinação/não vacinação é discutível o uso de questões com respostas abertas ou fechadas. Após um levantamento exaustivo das razões relacionadas com a adesão e recusa de vacinação apresentadas noutros estudos, optou-se por incluir as principais destas como opções de res- 
postas fechadas no nosso questionário e associar uma resposta aberta ("Outro") para motivos não contemplados. Estes foram agrupados em categorias, processo a que se associam perdas de dados e imprecisões. Alguns estudos aceitam apenas uma razão válida, no entanto, optou-se por aceitar até três respostas. Embora se possa conceber a existência de uma razão principal para um indivíduo aderir ou recusar a vacinação, é mais plausivel que esta decisão seja multifactorial. Contudo, esta opção não é livre de crítica, uma vez que disponibilizar diversas hipóteses pode induzir a selecção de razões acessórias, atribuindo-lhes o mesmo peso das principais.

Retrospectivamente seria pertinente, para uma melhor caracterização, que algumas variáveis tivessem sido mais bem documentadas, nomeadamente, especificando quais as campanhas de incentivo que receberam no local de trabalho, como por exemplo posters em áreas estratégicas, panfletos, conferências sobre o tema, sessões no serviço, etc. e referenciando-o geograficamente. Poderiam, ainda, ter constado no questionário outras variáveis, para uma melhor caracterização da amostra, como a idade dos inquiridos.

Outros critérios, passiveis de serem avaliados, embora diferentes dos objectivos inicialmente propostos, poderiam ser saber se o Interno se vacinou no ano anterior (pois, para este último item, alguns estudos concluíram que quem normalmente se vacina continua a fazê-lo, podendo, tratar-se, portanto, de uma questão de hábito) ou o nível de conhecimentos que os inquiridos têm sobre a vacina.

\section{Discussão dos resultados}

Na totalidade da nossa amostra ( $n=136$ ), entre os dias 20 e 27 de Outubro de 2006, encontrámos uma taxa de vacinação de $33,1 \%(n=45)$. Tendo em conta que estudos ${ }^{6,8}$ sugerem uma taxa minima de $80 \%$ para se obter uma imunidade em grupo, esta taxa pode ser considerada baixa. Uma vez que não existe nenhum estudo nacional sobre o assunto e que os estudos estrangeiros abrangem não Internos do Ano Comum mas sim profissionais de saúde em geral e Internos de especialidade, tornase dificil a comparação. Nos profissionais de saúde, as taxas variam entre 2,1 a $82 \% .{ }^{14} \mathrm{Em}$ Internos de especialidade, as taxas variam entre 38,3 a $97 \% .^{15-17}$ É sabido que esta variabilidade se deve sobretudo a características das campanhas e factores políticos ou culturais, algumas das variáveis que se tentaram estudar neste trabalho. Por outro lado, considerando o possivel viés metodológico, já referido, pode-se supor que esta taxa, apesar de baixa, se encontra inflacionada em relação à real taxa de vacinação de Internos do Ano Comum.

Ao caracterizar a amostra, verificou-se que o sexo feminino representa $60,3 \%(\mathrm{n}=82)$ e o masculino $39,7 \%$ $(\mathrm{n}=54)$, tendo a distribuição da taxa de vacinação por sexos revelado que $37,8 \%$ $(\mathrm{n}=31)$ das mulheres se vacinaram para esta época contra $25,9 \%(n=14)$ dos homens. No entanto, ao aplicar o teste estatístico, não se verificaram diferenças significativas quanto à proporção de vacinados/não vacinados relacionada com o sexo.

De entre a população que se encontra vacinada para a gripe sazonal, os motivos apontados como principais para o fazer são proteger o próprio contra a doença $(91,1 \%, n=41)$, proteger os doentes $(77,8 \%, \mathrm{n}=35)$ e o acesso fácil à vacina $(53,3 \%, n=24)$. Um estudo realizado ${ }^{15}$ nos Estados Unidos, com 196 Internos de especialidade, demonstrou que $93,3 \%$ dos inquiridos responderam "protecção do próprio", valor semelhante ao encontrado no nosso estudo, e $45,3 \%$ "protecção dos doentes", valor este bastante inferior ao encontrado. Deduz-se assim que, para esta amostra, os interesses do doente são consi- 
derados um importante factor mobilizador para a vacinação. Num estudo de revisão, ${ }^{14}$ realizado com profissionais de saúde, encontraram-se percentagens de resposta que oscilam entre 11 e $58 \%$ quanto à acessibilidade da vacina como motivo para a vacinação. Esta grande variabilidade compreende-se na medida em que o acesso à vacina depende directamente das características de acessibilidade presentes em cada meio. O nosso estudo, ao revelar que cerca de $53 \%$ dos indivíduos vacinados consideram este motivo relevante para a sua vacinação, demonstra a importância que projectos facilitadores dos acessos poderão ter na vacinação.

De entre a população que não se encontra vacinada para a gripe sazonal, os motivos que esta aponta como principais para não o fazer são o desinteresse $(35,2 \%, n=32)$, a falta de tempo $(31,9 \%, n=29)$, o considerar a vacina pouco eficaz $(28,6 \%, n=26)$, o não considerar ter "grande risco de ser contagiado" $(20,9 \%, n=19)$, as preocupações com efeitos adversos $(19,8 \%, n=18)$ e o não considerar que o doente corra ris$\cos$ com a sua não vacinação $(18,7 \%$, $\mathrm{n}=17$ ). Outros estudos ${ }^{15,16}$ confirmam estes motivos como dos mais importantes. Apesar da eficácia da vacina estar comprovada, ${ }^{3}$ constata-se que esta população, supostamente informada e actualizada, mantém dúvidas sobre esta matéria. Um grande número de inquiridos $(20,9 \%, n=19)$ explicitou, na opção «Outro. Gual?» um motivo para a não vacinação que não foi possível categorizar, o que revela uma maior heterogeneidade de motivos para a não vacinação do que para vacinação.

É de salientar que muitos dos não vacinados pretendem fazê-lo (33\%, $\mathrm{n}=30)$. Apesar do questionário não permitir justificar, caso a caso, por que motivo estes indivíduos ainda não o fizeram, algumas pistas são-nos deixadas nos motivos para a não vacinação: "não tive tempo", "falta de disponibilidade da va- cina", "inscreveu-se para ser vacinado e aguarda a aplicação da vacina». Estes são alguns factores modificáveis sobre os quais é possivel actuar.

Quanto à existência de estratégias de incentivo e relativamente ao conhecimento de alguma campanha para a vacinação contra a gripe sazonal, constata-se que $69,1 \%(n=94)$ dos inquiridos responde afirmativamente. No entanto, apesar de se tratar de uma elevada percentagem, ao aplicar o teste estatístico verifica-se não existirem diferenças significativas na proporção de vacinados/não vacinados com o conhecimento de campanhas $(p=0,52)$. Em estudos, ${ }^{17,20-22}$ em que se avalia a taxa de vacinados antes e após a realização de campanhas específicas e dirigidas, essa correlação encontra-se bem demarcada. Num deles, ${ }^{17}$ a taxa de vacinados, antes e após a campanha, foi da ordem dos $24 \%$ antes para $97 \%$ após. Assim, a não existência desta correlação no nosso trabalho poder-se-á dever à eventualidade das campanhas não terem sido efectivas, embora se desconheça com precisão quais as estratégias aplicadas no meio em que os inquiridos se inserem. Sabe-se no entanto que, de entre as vias de conhecimento da campanha, o local de trabalho $(78,7 \%$, $\mathrm{n}=74)$ e a comunicação social $(46,8 \%$, $\mathrm{n}=44$ ) foram as mais referidas.

A rotatividade dos Internos do Ano Comum entre o Centro de Saúde e os Hospitais, ilustrada pela presença, à data do inquérito, de apenas 14\% $(n=19)$ no Centro de Saúde, justifica os valores muito baixos de campanhas no primeiro $(31,1 \%, \mathrm{n}=23)$. Da mesma forma se compreende que dos $64,4 \%$ $(n=29)$ que a adquiriram gratuitamente no local de trabalho, 3,4\% $(n=1)$ a obtiveram no Centro de Saúde face a $96,6 \%(n=28)$ que a obtiveram no Hospital. É de notar que, idealmente, todos os profissionais de saúde, especialmente os com maior contacto com os doentes de risco, deveriam poder obtê-la gra- 
tuitamente.

É de referir que $81,6 \%(n=111)$ considera a vacinação contra a gripe sazonal importante ou muito importante na classe médica, no entanto apenas $33,1 \%$ dos inquiridos se vacinou. Nos estudos consultados não existem dados sobre esta questão. A maioria dos inquiridos, $88,2 \%(n=120)$, considera, e correctamente, que pertence a um grupo de risco numa percentagem semelhante à encontrada noutro estudo, ${ }^{15} 81,6 \%$. Estes dois factores, quando confrontados com a taxa de vacinação encontrada, $33,1 \%(n=45)$, revelaram uma certa incoerência entre a posição dos inquiridos face à vacinação dos profissionais de saúde e os comportamentos adoptados em relação a esta.

\section{CONCLUSÕES E RECOMENDACÕ̃ES}

A maioria dos inquiridos teve conhecimento de campanhas para a vacinação contra a gripe sazonal essencialmente no local de trabalho $(78,7 \%)$. No entanto, estas não aparentam ter sido efectivas, uma vez que não se encontram diferenças significativas na proporção de vacinados/não vacinados com o conhecimento da campanha. Este facto poderá reforçar a baixa taxa de vacinação encontrada $(33,1 \%)$. Contudo, a importância atribuída pelos Internos do Ano Comum à vacinação, o facto de se considerarem um grupo de risco e a existência de uma taxa considerável dos que pretendem vacinar-se (33\%), parecem constituir uma boa plataforma para futuras campanhas bem dirigidas.

De acordo com as motivações encontradas conclui-se que ter fácil acesso à vacina, ter a percepção de que esta protege os profissionais da saúde e os doentes, são factores que mobilizam à vacinação. Enquanto que não ter tempo, o desinteresse e o considerar a vacina pouco eficaz são obstáculos à vacinação. Sugere-se que futuras campanhas incidam nestes factores.

Recomenda-se, por fim, a realização de um estudo, com uma amostra aleatória e representativa dos profissionais de saúde, na qual se incluiria esta população de estudo, de modo a avaliar, de uma forma sistematizada, as motivações para a vacinação/não vacinação destes indivíduos, uma vez que estes poderão divergir consoante o grupo profissional a que pertencem. De facto, sabe-se que de entre as várias formas de incentivo à vacinação, a presença de um líder neste projecto ocupa um papel central. ${ }^{14}$ Estando os Internos do Ano Comum num período de formação, a proximidade de exemplos a seguir no seu meio de trabalho adquire um maior relevo.

\section{REFERÊNCIAS BIBLIOGRÁFICAS}

1. European Influenza Surveillance Scheme. Disponivel em : URL: http://www.eiss.org/ html/faq_influenza.html [acedido em 08/11/ /2007].

2. Observatório Nacional de Saúde. Vacinação anti-gripal: estudo da cobertura da população portuguesa de 1998/99 a 2002/2003. Estudo na amostra ECOS. Disponível em: URL: http://www.onsa.pt/conteu/estudos/estud_vacina-anti-gripal_onsa.pdf [acedido em 30/10/2007].

3. World Health Organization. Influenza vaccines: WHO position paper. Wkly Epidemiol Rep 2005; 80 (33): 279-87. Disponivel em: URL: http://www.who.int/immunization/wer803 3influenza_August2005_position_paper.pdf [acedido em 08/11/2007].

4. Direcção-Geral de Saúde. Gripe: vacinação contra a gripe em 2006/2007. Lisboa: DGS; 2006. Disponivel em: URL: http://www.dgs. pt/umpoad/membro.id/ficheiros/i008256.pdf [acedido em 30/10/2007].

5. World Health Organization. Recommended composition of influenza virus vaccine for use in the 2006-2007 influenza season. Disponivel em: URL: http://www.who.int/csr/disease/influenza/2007northreport.pdf [acedido em 02/11/2007].

6. Smith NM, Bresee JS, Shay DK, Uyeki TM, Cox NJ, Strikas RA. Prevention and control of influenza: recommendations of the Ad- 
visory Committee on Immunization Practices (ACIP). MMWR Recomm Rep 2006 Jul 28; 55 (RR-10): 1-42.

7. Saxén H, Virtanen M. Randomized placebo-controlled double blind study on the efficacy of influenza immunization on absenteeism of health care workers. Pediatr Infect Dis J 1999 Sep; 18 (9): 779-83.

8. Salgado CD, Giannetta ET, Hayden FG, Farr BM. Preventing nosocomial influenza by improving the vaccine acceptance rate of clinicians. Infect Control Hosp Epidemiol 2004 Nov; 25 (11): 923-8.

9. Carman WF, Elder AG, Wallace LA, McAulay K, Walker A, Murray GD, et al. Effects of influenza vaccination of health-care workers on mortality of elderly people in long-term care: a randomised controlled trial. Lancet $2000 \mathrm{Jan}$ 8; 355 (9198): 93-7.

10. Potter J, Stott DJ, Roberts MA, Elder AG, O’Donnell B, Knight PV, et al. Influenza vaccination of health care workers in long-term-care hospitals reduces the mortality of elderly patients. J Infect Dis 1997 Jan; 175 (1): 1-6.

11. Wilde JA, McMillan JA, Serwint J, Butta J, O`Riordan MA, Steinhoff MC. Effectiveness of influenza vaccine in health professionals: a randomized trial. JAMA 1999 Mar 10; 281 (10): 908-13.

12. Lester RT, McGeer A, Tomlinson G, Detsky AS. Use of, effectiveness of, and attitudes regarding influenza vaccine among house staff. Infect Control Hosp Epidemiol 2003 Nov; 24 (11): 839-44.

13. Nguyen-Van-Tam J, Granfield R, Pearson J, Fleming D, Keating N. Do influenza epidemics affect patterns of sickness absence among British hospital staff? Infect Control Hosp Epidemiol 1999 Oct; 20 (10): 691-4.

14. Hofmann F, Ferracin C, Marsh G, Dumas $\mathrm{R}$. Influenza vaccination of healthcare workers: a literature review of attitudes and beliefs. Infection. 2006 Jun. 34(3) 142-147

15. Wodi AP, Samy S, Ezeanolue E, Lamour $R$, Patel R, Budnick LD, et al. Influenza vaccine: immunization rates, knowledge, and attitudes of resident physicians in an urban teaching hospital. Infect Control Hosp Epidemiol 2005 Nov; 26 (11): 867-73.

16. Toy WC, Janosky JE, Laird SB. Influenza immunization of medical residents: knowledge, attitudes, and behaviours. Am J Infect Control 2005 Oct; 33 (8): 473-5.

17. Fedson DS. Influenza vaccination of medical residents at the University of Virginia: 1986 to 1994. Infect Control Hosp Epidemiol 1996 Jul; 17 (7): 431-3.
18. Portaria no $1499 / 2004$, de 28 de Dezembro. Diário da República I - série B, nº 302 (28 de Dezembro de 2004), p. 7357-61.

19. Diário da República - II série, $n^{\circ} 216$ (10 de Novembro de 2005), p. 15863-64.

20. Goldstein AO, Kincade JE, Gamble G, Bearman RS. Policies and practices for improving influenza immunisation rates among healthcare workers. Infect Control Hosp Epidemiol 2004 Nov; 25(11): 908-11.

21. Song JY, Park CW, Jeong HW, Cheong HJ, Kim WJ, Kim SR. Effect of a hospital campaign for influenza vaccination of healthcare workers. Infect Control Hosp Epidemiol 2006 Jun; 27 (6): 612-7.

22. xxii Sartor C, Tissot-Dupont H, Zandotti C, Martin F, Roques P, Drancourt M. Use of a mobile cart influenza program for vaccination of hospital employees. Infect Control Hosp Epidemiol 2004 Nov; 25 (11): 918-22.

\section{Restante bibliografia}

1. Kasper DL, Braunwald E, Fauci A, Hauser SL, Longo DL, Jameson JL, editors. Harrison's Principles of Internal Medicine. 16th ed. New York: Mc Graw-Hill; 2004.

2. Canada National Advisory Committee on Immunization (NACI). Statement on influenza vaccination for the 2006-2007 season. Canada Communicable Disease Report 2006 June 15; 32: 1-28.

3. Observatório Nacional de Saúde. Gripe das aves: preocupações e conhecimentos da população: Abril-Novembro de 2005: uma nota preliminar. Lisboa: Observatório Nacional de Saúde; 2006.

4. World Health Organisation. Guidelines on the use of vaccines and antivirals during influenza pandemics; 2004. Disponivel em: URL: http://www.who.int/csr/resources/publications/influenza/WHO_CDS_CSR_RMD_2004_ 8/en [acedido em 30/10/2007].

5. Centers of Disease Control and Prevention (CDC). Interventions to increase influenza vaccination of health-care workers: California and Minnesota. MMWR Morb Mortal Wkly Rep 2005 Mar 4; 54 (8): 196-9.

6. Cowan AE, Winston CA, Davis MM, Wortley PM, Clark SJ. Influenza vaccination status and influenza related perspectives and practices among US physicians. Am J Infect Control 2006 May; 34 (4): 164-9.

7. Walker FJ, Singleton JA, Lu P, Wooten $\mathrm{KG}$, Strikas RA. Influenza vaccination of healthcare workers in the United States, 1989-2002. Infect Control Hosp Epidemiol 2006 Mar; 27 (3): 257-65. 
8. Talbot TR, Bradley SE, Cosgrove SE, Ruef C, Siegel JD, Weber DJ. Influenza vaccination of healthcare workers and vaccine allocation for healthcare workers during vaccine shortages. Infect Control Hosp Epidemiol 2005 Nov; 26 (11): 882-90.

9. Martinello RA, Jones L, Topal JE. Correlation between healthcare workers' knowledge of influenza vaccine and vaccine receipt. Infect Control Hosp Epidemiol 2003 Nov; 24 (11) 845-7.

10. Steiner M, Vermeulen LC, Mullahy J, Hayney MS. Factors influencing decisions regarding influenza vaccination and treatment: a survey of healthcare workers. Infect Control Hosp Epidemiol. 2002 Oct; 23 (10): 625-7.

11. Manuel DG, Henry B, Hockin J, Naus M. Health behavior associated with influenza vaccination among healthcare workers in longterm-care facilities. Infect Control Hosp Epidemiol 2002 Oct; 23 (10): 609-14.

12. Bearman G, Fuentes L, Van Vorenkamp JL, Drusin LM. Vaccination without documentation: influenza immunization among medical residents at a tertiary-care medical center. Infect Control Hosp Epidemiol 2003 Aug; 24 (8): 626-8.

13. Stephenson I, Nicholson KG. Influenza: vaccination and treatment. Eur Resp J 2001 Jun; 17 (6): 1282-93.

14. Smedley J, Palmer C, Baird J, Barker M. A survey of the delivery and uptake of influenza vaccine among health care workers. Occup Med 2002 Aug; 52 (5): 271-6.

15. Harrison J, Abbott P. Vaccination against influenza: UK healthcare workers not on-message. Occup Med (London) 2002 Aug; 52 (5): 277-9.

16. Qureshi AM, Hughes NJ, Murphy E, Primrose WR. Factors influencing uptake of influenza vaccination among hospital-based health care workers. Occup Med (London) 2004 May; 54 (3): 197-201.

17. Galicia-García MD, González-Torga A, García-González C, Fuster-Pérez M, GarrigósGordo I, López-Fresneña, et al. Vacunación de gripe en trabajadores sanitarios. Por qué se vacunan y por qué no se vacunan. Enferm Infecc Microbiol Clin 2006 Ago-Sep; 24 (7): 413-7.

18. Tapiainen T, Bär G, Schaad UB, Heininger U. Influenza vaccination among healthcare workers in a university children's hospital. Infect Control Hosp Epidemiol 2005 Nov; 26 (11): 855-8.

19. Piccirillo B, Gaeta T. Survey on use of and attitudes toward influenza vaccination among emergency department staff in a New
York metropolitan hospital. Infect Control Hosp Epidemiol 2006 Jun; 27 (6): 618-22.

20. Watanakunakorn C, Ellis G, Gemmel D. Attitude of healthcare personnel regarding influenza immunization. Infect Control Hosp Epidemiol 1993 Jan; 14 (1): 17-20.

21. Hak E, Hoes AW, Verheij TJ. Influenza vaccinations: who needs them and when? Drugs 2002; 63 (17): 2413-20.

22. Thomas RE, Jefferson TO, Demicheli V, Rivetti D. Influenza vaccination for health-care workers who work with elderly people in institutions: a systematic review. Lancet Infect Dis 2006 May; 6 (5): 273-9.

23. O'Reilly FN, Cran GW, Stevens AB. Factors affecting influenza vaccine uptake among health care workers. Occup Med (Lond) 2005 Sep; 55 (6): 474-9.

24. Doebbeling BN, Edmond MB, Davis CS, Woodin JR, Zeitler RR. Influenza vaccination of health care workers: evaluation of factors that are important in acceptance. Prev Med 1997 Jan-Fev; 26 (1): 68-77.

25. Kuzma JW. Basic statistics for the health sciences. 3rd ed. Mountain View, CA: Mayfield Pub Co; 1998. 3rd edition: Publishing Company (USA); 1998.

26. Matthews DE, Farewell VT. Using and understanding medical statistics. 2nd ed. Basel: Karger; 1988.

\section{Agradecimentos}

Agradecemos à Mestre Helena Almeida pelo apoio e disponibilidade prestados, ao Eng. Miguel Nave pela execução do site da Internet no qual o questionário ficou alojado, ao Dr. Hernâni Resendes por nos ter facultado uma lista de $e$-mails de Internos do Ano Comum e à Dra. Laura Reis pela ajuda fornecida no tratamento estatístico. Por fim, um agradecimento especial a todos os que gentilmente responderam ao questionário, permitindo a realização deste trabalho.

Endereço para correspondência:

Patrícia Isabel Ribeiro Diogo Pedro

Praceta Alexandre O'Neill, no $4,2^{\circ}$ Dto.

2675-468 Odivelas

Tel:- 964727134

E-mail: patypedro@clix.pt

Recebido em 21/11/2006

Aceite para publicação em 02/10/2007 


\section{QUESTIONÁRIO}

Somos um grupo de alunos do $6^{\circ}$ ano de Medicina da Faculdade de Ciências Médicas de Lisboa. No âmbito da cadeira de Saúde Pública, propomo-nos investigar a taxa de adesão à vacinacão da gripe sazonal de 2006/2007 e as suas motivaç̃ões, entre a população de Internos do Ano Comum. A sua colaboração é indispensável para 0 sucesso desta investigação. Agradecemos, desde já, a sua colaboração!

1. É Interno do Ano Comum a exercer em Portugal?

$$
S \square N \square
$$

2. Qual o seu Local de trabalho? Centro de Saúde Hospital Distrital Hospital Central

3. Sexo

Feminino

Masculino

4. Fez a vacina da gripe este ano? $S \square \quad \mathrm{N} \square$

(se respondeu Não passe à pergunta 7)

5. Se respondeu Sim na pergunta 4 que motivos considera serem os mais importantes na sua decisão? (Coloque as 3 principais razões)
a) Protege-me da doença
b) Protejo os doentes
c) Tenho fácil acesso à vacina da gripe
d) Tenho patologia que constitui indicação para ser vacinado
e) Porque estou grávida
f) Outro

Qual?

6. Como obteve a vacina para a gripe?
a) Comprei
b) Adquiri gratuitamente no local de trabalho
Onde? Centro de Saúde $\square \quad$ Hospital
c) Adquiri de outra forma
Qual?

7. Se respondeu Não na pergunta 4, quais os motivos?

(Coloque as 3 principais razões)
a) Não considero ter grande risco de ser contagiado
b) Não considero que o doente corra riscos se não me vacinar para a gripe
c) Efeitos adversos da vacina da gripe
d) Contra indicacões médicas
e) Não tive tempo 


\section{EstudOS ORIGINAIS}

f) Considero a vacina para a gripe pouco eficaz

g) Desinteresse

h) Outro.

Qual?

8. Se não se vacinou para a gripe, pretende fazê-lo?

$\mathrm{S} \square \mathrm{N} \square$

9. Teve conhecimento, este ano, de alguma campanha para vacinação contra a gripe sazonal?

$\mathrm{S} \square \mathrm{N} \square$

Se Sim, como? (Coloque até 2 respostas)

a) Comunicação social

b) Internet

c) Local de trabalho

Onde? Centro de Saúde $\square \quad$ Hospital $\square$

d) Família

e) Outro

Qual?

10. Que grau de importância atribui à vacinação para a gripe sazonal na classe médica?
a) Muito importante
b) Importante
c) Pouco importante
d) Nada importante

11. Acha que os médicos constituem um grupo de risco para a gripe sazonal?

$\mathrm{S} \square \mathrm{N} \square$ 